\title{
“DOS ÓRGÃOS GOVERNAMENTAIS NÃO ESPERO NADA A ESSA ALTURA DA MINHA VIDA PROFISSIONAL" - UM DEBATE SOBRE VALORIZAÇÃO DOCENTE SOB A PERSPECTIVA DE PROFESSORES
}

\author{
Fernanda Ribeiro Paz ${ }^{1}$ \\ Ennia Débora Passos Braga Pires ${ }^{2}$ \\ Marília do Amparo Alves Gomes ${ }^{3}$
}

\section{RESUMO}

Este estudo busca identificar qual a concepção de valorização docente dos professores da rede pública municipal de ensino de um município de médio porte do estado da Bahia. Seguindo uma abordagem qualitativa, os dados foram coletados por meio de entrevistas semiestruturadas com os sujeitos envolvidos e análise documental. Os resultados encontrados permitem-nos inferir que os professores participantes da pesquisa acreditam que para a efetivação da valorização do professor é necessário que sejam assegurados os elementos relativos à valorização desta profissão: formação adequada para exercer a sua função, carreira progressiva definida, um salário justo e compatível e condições propícias para o desenvolvimento do ensino e aprendizagem. Além disso, o estudo

\footnotetext{
${ }^{1}$ Mestre em Educação pela Universidade Estadual do Sudoeste da Bahia (UESB) - Programa de Pós-Graduação em Educação PPGED/UESB. Membro do Grupo de Pesquisa em Ludicidade, Didática, Política e Práxis Educacional (LUDIPPE). Professora do Ensino Fundamental em Vitória da Conquista - Bahia. ORCID: https://orcid.org/0000-00028391-5999. Email: nandapaz20@gmail.com

2 Doutora em Educação pela Universidade Estadual de Campinas (UNICAMP). Docente do Programa de Pós-Graduação em Educação PPGED da Universidade Estadual do Sudoeste da Bahia (UESB). Líder do Grupo de Pesquisa em Ludicidade, Didática, Política e Práxis Educacional (LUDIPPE). ORCID: https://orcid.org/0000-0003-3924-4996 . Email: enniadebora@uesb.edu.br

3 Mestre em Educação pela Universidade Estadual do Sudoeste da Bahia (UESB)-Programa de Pós-Graduação em Educação PPGED/UESB. Membro do Grupo de Pesquisa em Ludicidade, Didática, Política e Práxis Educacional - (LUDIPPE) e Grupo de Estudos e Pesquisas em Políticas para a Educação Superior (GEPPS). ORCID: https://orcid.org/00000002-2321-3813. E-mail: mariliaamparo@gmail.com
} 
conclui que somente o amparo da lei, por si só, não garante o atendimento das reivindicações históricas e aponta para a necessária e importante participação coletiva da classe docente em diversas instâncias e espaços de reivindicações.

Palavras-chave: Valorização docente. Políticas públicas. Reivindicações.

\section{“I DO NOT EXPECT ANYTHING FROM GOVERNMENT AGENCIES AT THIS POINT IN MY PROFESSIONAL LIFE" - A DEBATE ON TEACHER APPRECIATION FROM THE PERSPECTIVE OF TEACHERS}

\section{ABSTRACT}

This study sought to identify the concept of teacher valorization _ of the public school system teachers in a medium-sized municipality in the state of Bahia. Following a qualitative approach, data were collected through semi-structured interviews with the subjects involved and documentary analysis. The results found allow us to infer that the teachers participating in the research believe that in order for the teacher to be valued is necessary to ensure the elements that involve the valorization of this profession: adequate training to perform his/her function, defined progressive career, a fair salary and compatible and favorable conditions for the development of teaching and learning. In addition, the study concludes that only the protection of the law, by itself, does not guarantee the fulfillment of historical claims and issues to the necessary and important collective participation of the teaching class in different instances and spaces for demanding recognition.

Keywords Teacher appreciation. Public policy. Claims. 


\section{RESUMEN}

Este estudio buscó identificar el concepto de valorización docente de los docentes del sistema de escuelas públicas municipales de un municipio de tamaño medio del estado de Bahía. Siguiendo un enfoque cualitativo, los datos fueron recolectados a través de entrevistas semiestructuradas con los sujetos involucrados y análisis documental. Los resultados encontrados permiten inferir que los docentes participantes en la investigación creen que para que el docente sea valorado es necesario asegurar los elementos que implican la valorización de esta profesión: una formación adecuada para el desempeño de su función, una carrera progresiva definida, un salario justo y condiciones compatibles y favorables para el desarrollo de la enseñanza y el aprendizaje. Además, el estudio concluye que solo la protección de la ley, por sí sola, no garantiza el cumplimiento de reclamaciones históricas y apunta a la necesaria e importante participación colectiva de la clase docente en diferentes instancias y espacios de reivindicación.

Palabras clave: Agradecimiento al maestro. Políticas públicas. Reclamación.

\section{INTRODUÇÃO}

Este artigo é resultado de uma pesquisa desenvolvida no ano de 2019, cujo objetivo principal foi identificar qual a concepção de valorização docente dos professores da rede pública municipal de ensino de um município de médio porte do estado da Bahia. A pesquisa foi realizada em uma Escola Municipal de Ensino Fundamental, contando com a participação de quatro professoras, 
três atuando nos anos inicias do Ensino Fundamental e uma atuando nos anos finais.

A pesquisa cumpriu todos os requisitos solicitados pelo Conselho de Ética. Desse modo, os indivíduos convidados à participação foram esclarecidos através do Termo de Consentimento Livre e Esclarecido (TCLE) sobre os propósitos da investigação, cuidados que seriam tomados quanto à preservação do entrevistado e quanto a sua participação voluntária. Por esse motivo, todos os nomes aqui utilizados são fictícios.

Para alcançar o objetivo desta pesquisa, utilizou-se, mediante uma abordagem qualitativa, entrevistas semiestruturadas com os sujeitos envolvidos, visto que para esse fim esta estratégia mostrouse mais adequada, pois a entrevista semiestrutura "se desenrola a partir de um esquema básico, porém não aplicado rigidamente, permitindo que o entrevistador faça as necessárias adaptações" (LUDKE; ANDRÉ, 1986, p. 34).

Além disso, foram realizadas pesquisas documentais, com o intuito de identificar a concepção de valorização docente presente em documentos legislativos nacionais, tais como a Constituição Federal de 1988, a Lei 9394/96 (Lei de Diretrizes e Bases da Educação Nacional - LDB) e o Plano Nacional de Educação (PNE/2014-2024).

Quanto ao tema da pesquisa, esclarecemos que conceituar o termo valorização docente constitui-se um desafio; assim, é preciso responder a algumas questões para melhor esclarecimento do seu significado: em que consiste a valorização do professor? Quais elementos podem assegurar que esse profissional seja valorizado?

No que consiste a valorização docente, Farias (2013, p. 338) aponta que a

[...] valorização é o reconhecimento da atividade docente, no sentido de propiciar um salário que garanta boas condições de vida para o professor e para sua família, boa formação capaz de dar subsídios para execução de um trabalho de qualidade. É importante destacar que os dois aspectos citados só surtem efeito se estiverem aliados a condições propícias para o bom 
desenvolvimento dos processos de ensino e aprendizagem.

É por meio de políticas públicas educacionais que os elementos que compõem a valorização da profissão são assegurados. Defendemos, aqui, a formação inicial e continuada, remuneração, carreira, condições de trabalho e saúde como pilares indissociáveis para a valorização do professor.

VALORIZAÇÃO DOCENTE NO BRASIL: uma breve incursão histórica

As políticas públicas educacionais implementadas nas últimas décadas no Brasil foram importantes para as mudanças que influenciaram a carreira, a remuneração, a formação e as condições de trabalho e saúde dos professores, o que, nem sempre, foi assim. Nos últimos 40 anos, os sentidos sobre valorização do professor foram se definindo e se fixando no âmbito do embate das propostas formuladas por instâncias da sociedade civil e da sociedade política.

No final dos anos 1980, o Brasil buscou delimitar os requerimentos necessários ao exercício da docência, "[...] balizados por uma política de caráter emergencial voltado a enfrentar a carência de professores face o contínuo crescimento de demanda por escolarização" (WEBER, 2015, p. 497). Essa questão como característica emergencial tornou-se demanda de luta quando a educação passou a ser vista como objeto em favor da democracia e, neste contexto, entendida como direito social básico e de qualidade.

Como efeito da demanda por escolarização, a formação dos professores entra em pauta nos debates educacionais que teciam críticas ao trabalho docente desenvolvido sem preparação específica e sem formação pedagógica. Promulgada nos anos de 1970, em pleno regime autoritário, a Lei $n^{\circ} 5.692 / 1971$ remete a formação do Magistério a uma das muitas habilitações de nível médio de caráter profissionalizante, assim como admite formação em licenciatura curta para os professores dos anos finais do fundamental, o antigo $2^{\circ} \mathrm{grau}$ (Art. 30). 
Devido ao caráter tecnicista, voltado para instrumentos e métodos, a formação docente passou a ser objeto de estudos específicos em debates social e acadêmico. As discussões acerca da dimensão profissional estenderam-se em busca do reconhecimento do caráter profissional docente associado à valorização desses profissionais e se findaram quando a Constituição Federal (CF) de 1988 incorporou no inciso V, do art. 206, os princípios aos quais o ensino serve de base. Além disso, por meio da Emenda Constitucional $n^{\circ} 53$, de 19 de dezembro de 2006, a CF refere-se não somente à remuneração por habilitação, mas às condições de trabalho.

Ampliando a CF/1988, a atual Lei de Diretrizes e Bases da Educação, Lei no 9.394/96, prevê no artigo 67 a promoção da valorização dos professores. O regimento dispõe que a valorização docente será garantida inclusive nos planos de carreira e estatutos:

\footnotetext{
I - Ingresso exclusivamente por concurso público de provas e títulos.

II - Aperfeiçoamento profissional continuado, inclusive com licenciamento periódico remunerado para esse fim.

III - Piso salarial profissional.

IV - Progressão funcional baseada na titulação ou habilitação, e na avaliação do desempenho.

$\checkmark$ - Período reservado a estudos, planejamento e avaliação, incluído na carga de trabalho.

$\mathrm{VI}$ - Condições adequadas de trabalho (BRASIL, 1996).
}

Esses incisos apresentam os elementos que asseguram a valorização do profissional do magistério, pois refletem sobre a necessidade de titulação acadêmica de qualidade, enquadramento numa carreira que pressupõe estabilidade, progressão, formação, valorização salarial e condições adequadas de trabalho.

No início dos anos 1980, a Confederação Nacional dos Trabalhadores da Educação (CNTE) formulava a concepção de docente como trabalhador em educação, e suas reivindicações estavam concentradas em torno de salários condignos e condições de trabalho apropriadas, mas somente em 1993 a CNTE acresceu à sua luta pela definição do piso salarial nacional o aperfeiçoamento 
contínuo do professorado; essas considerações foram pleiteadas pela Associação Nacional pela Formação dos Profissionais da Educação (Anfope) e por outras entidades.

Outro importante marco é o Plano Nacional de Educação (PNE), sancionado em 26 de junho de 2014. A Lei no 13.005/2014 apresenta desafios relacionados à evolução dos indicadores de alfabetização e inclusão, a expansão do ensino profissionalizante para jovens e adultos, financiamento e valorização dos profissionais do magistério.

Dentre as metas que abordam a questão da valorização docente, 20\% abordam questões relativas aos eixos: formação, carreira e salário, das quais as metas 15, 16, 17 e 18 têm como alvo a valorização dos professores da educação básica da rede pública de ensino.

No ano de 2014, a Conferência Nacional de Educação apresentou uma concepção de valorização docente que rompia com a visão restrita relativa apenas à formação. $O$ documento definia que a valorização dos profissionais docentes envolve, de maneira articulada, a formação inicial e continuada, carreira, salários condizentes e condições de trabalhos favoráveis (DOURADO, 2016).

Com isso, ressaltamos que o profissional é valorizado quando tem boas condições de trabalho, formação adequada para exercer a sua função, carreira progressiva definida, um salário justo e compatível; esses pilares são norteadores para a valorização do docente.

\section{PILARES DA VALORIZAÇÃO DOCENTE}

Estudos como os de Gatti, Barreto e André (2011), Monlevade (2000), Oliveira (2011), Valente e Romano (2002) e Farias (2013) concordam que a valorização do professor implica diretamente a qualidade da educação, todavia, como apontam Gatti, Barreto e André (2011), para a melhoria da educação é imprescindível o investimento nos pilares que compõem a valorização social da carreira docente.

No contexto das reformas educacionais, o professor é responsabilizado por grande parte dos insucessos escolares, essa 
ideia difunde que a maneira de melhorar a educação está em investir especialmente na sua formação, já que ele não está preparado para executar da melhor forma o seu trabalho. Todavia, pouco se fala acerca da necessidade de melhorar as condições de trabalho, a remuneração, o número de alunos por sala e carreiras estruturadas, estruturas físicas das escolas, dentre outros aspectos.

Nesta direção, é necessário compreendermos os elementos que envolvem a valorização docente. O primeiro a ser pontuado aqui é a formação. O Plano Nacional de Educação (PNE/2014-2024) aborda nas metas 15 e 16 a formação como elemento de valorização docente.

Sobre a formação inicial, o Censo Escolar de 2009, publicado pelo Instituto Nacional de Estudos e Pesquisas Educacionais Anísio Teixeira (INEP) (BRASIL/MEC/INEP, 2009), apontou que o Brasil contava no período de 2005 com 1.882.961 professores vinculados à Educação Básica, dos quais 1.288.688 tinham nível superior completo (68,4\% do total).

Após 2016, prazo dado às redes públicas e privadas para cumprir a obrigatoriedade do diploma de nível superior para os docentes, no ano de 2010 até 2015 o número de diplomados cresceu cerca de 10 pontos percentuais. Em 2015, chegou a 76,4\%. O Censo Escolar de 2016 revela que 2,2 milhões de docentes atuam na Educação Básica brasileira; em relação à escolaridade, 77,5\% dos professores possuem nível superior completo, o que demonstra um percentual de crescimento significativo.

O Decreto $n^{\circ} 8.752 / 2016$, ao dispor sobre a Política Nacional de Formação de Profissionais do Magistério da Educação Básica, dentre os princípios estabelecidos, afirma que a formação inicial e continuada traduz-se em componentes essenciais para a profissionalização do professor.

Através de iniciativas em nível federal e estadual para oferecer formação em nível superior aos docentes em efetivo exercício nas redes públicas e ainda mediante ao aumento de cursos de licenciaturas, inclusive em instituições privadas, houve crescimento significativo de docentes com curso superior no Brasil.

Sobre a ênfase nas políticas de formação, Oliveira (2012, p. 36) destaca que a grande mobilização em torno da formação de 
professores envolvendo diferentes arranjos constitucionais foi "acompanhado com a crença de que a formação é a estratégia fundamental para a melhoria da educação".

Concordarmos que uma boa qualificação profissional do quadro que compõe a equipe escolar oferece melhores condições de aprendizagem, no entanto, entendemos também que políticas públicas apoiadas na formação como fator principal para a melhoria da qualidade educacional situam o docente no centro de uma responsabilidade que vai além da boa formação, como defende Scheibe (2010). Essa é uma visão muito restrita, pois, ao isolar fatores de diferentes ordens, deposita-se maior peso sobre a escola, ignorando fatores estruturais (OLIVEIRA, 2012).

Sobre o elemento remuneração, para melhor compreensão acerca desse pilar, faz-se necessário pontuarmos três conceitos: salário, vencimento e remuneração. O salário é o valor pago para o empregado pelo empregador, conforme a Consolidação das Leis de Trabalho (CLT); o vencimento é a retribuição pecuniária pelo exercício do cargo público, conforme estabelecido pela Lei $n^{\circ} 8.112^{4}$; nesse caso, tanto o salário como o vencimento são partes da remuneração, que, no caso do magistério, compõe-se do vencimento mais as vantagens pecuniárias, como as gratificações, auxílios, entre outros (GROCHOSKA, 2015).

A meta 17 do PNE (2014-2024) é direcionada para a valorização docente, buscando equiparar o rendimento médio dos professores da Educação Básica ao dos demais profissionais de outras áreas com escolaridade equivalente, já que "[...] a diferença entre o rendimento médio do magistério comparado com outras categorias profissionais é de 57\%, conforme apontado por documento do MEC sobre o PNE" (HYPOLITO, 2015, p. 525).

Mesmo com o crescimento desde o Piso Salarial Profissional Nacional (PSPN), estudos brasileiros indicam que professores recebem salários inferiores aos dos demais profissionais com formação equivalente, como citado por Jacomini, Nascimento e

\footnotetext{
${ }^{4}$ A Lei no 8.112 (BRASIL, 1990), que trata do Regime Jurídico dos Servidores Públicos, estabelece do Artigo 40 ao 48 as diferenças entre vencimento e remuneração.
} 
Thomazini (2018), que apontam os estudos de Barbosa Filho e Pessoa (2011), Alves e Pinto (2011), Jacomini, Alves e Camargo (2016).

Há também estudos, como o de Castro e loschpe (2007), que defendem que os docentes brasileiros recebem salários compatíveis com os dos demais profissionais com formação equivalente. Como a remuneração docente não constitui objeto central deste trabalho, não iremos aprofundar o debate nessa questão. Apenas sinalizamos o entendimento predominante no meio educacional, de que os baixos salários tendem a ter influência negativa na atuação dos professores e na atratividade da carreira, já que a remuneração implica diretamente a valorização do profissional.

Outro importante elemento da valorização docente é a carreira. Silva e Nunes (2019, p. 94) apontam o Plano de Carreira como "um instrumento legal específico da administração, que define a constituição da carreira, sua estrutura e funcionamento". É importante enfatizar que $\mathrm{O}$ conceito de carreira engloba conhecimentos específicos na área escolhida, as especializações, rotinas de trabalho, atividades extracurriculares, promoções recebidas, ou seja, toda experiência praticada ao longo da carreira e suas compensações.

A meta 18 do PNE (2014) estabelece o prazo de dois anos para a existência de planos de carreira para os profissionais da educação básica e superior de todo o sistema de ensino. Para os profissionais da Educação Básica pública, o plano de carreira deve tomar como referência o estabelecido no PSPN.

As estratégias da meta preveem também que, no mínimo, $90 \%$ dos profissionais do magistério e $50 \%$ dos demais ${ }^{5}$ profissionais da educação sejam ocupantes de cargos efetivos em exercício nas redes escolares, que os planos de carreira dos Estados, Distrito Federal e Munícipios prevejam licenças remuneradas e incentivos para qualificação profissional - nesse aspecto, incluem-se Mestrado e Doutorado (HYPOLITO, 2015).

A despeito disso, o aumento dos contratos temporários é crescente. Em alguns estados, o número de contratados corresponde

\footnotetext{
${ }^{5}$ Estes compõem desde o corpo administrativo da instituição de ensino ao corpo técnico, como monitores, auxiliares, secretários, assistentes de secretaria e demais profissionais que trabalham no espaço escolar.
} 
ao número de efetivos, como informa Oliveira (2003), o que promove a ausência e instabilidade na carreira, perda de garantias trabalhistas e previdenciárias oriundas das reformas do Aparelho do Estado.

Já que o plano de carreira, em conjunto com a remuneração, expressa o reconhecimento da experiência e da formação acadêmica dos profissionais docentes, contribuindo não só para o crescimento econômico, mas também para o reconhecimento social da profissão, entendemos a necessidade de efetivação dos planos, uma vez que a carreira assegura, juntamente com a formação, com a remuneração e com as condições de trabalho, a valorização do professor.

O último elemento a pontuarmos aqui diz respeito às condições de trabalho. Discutir as condições de trabalho do profissional docente implica em pensar nas condições de emprego desse profissional. De acordo com Brito, Prado e Nunes (2017), pressupõe pensar nas condições de emprego, na sua forma de contratação, remuneração, carreira e sua estabilidade.

No cenário das reformas do estado, o que rege são os princípios de eficiência e produtividade, visando ao crescimento econômico. Dentro dessa perspectiva as condições apresentadas para "melhores resultados" na educação envolvem maior flexibilização das leis e normas de contratação de professores, ampliação do tempo exigido para aposentadoria, premiação de professores e escolas por bons resultados nas avaliações externas (BRITO; PRADO; NUNES, 2017).

Essas demandas que cedem à lógica do mercado impactam diretamente nas condições de trabalho e na saúde dos docentes, tendo como reflexos o aumento da contratação temporária de professores, professores com duplas jornadas de trabalho, baixos salários, salas lotadas, dentre outros fatores de precarização do trabalho docente.

A intensificação e novas demandas que provocam a intensificação do trabalho docente podem acarretar graves consequências para a saúde do professor, como distúrbios de voz, estresse excessivo, dores diárias de cabeça e doenças psíquicas, como a Síndrome de Burnout. 


\section{VALORIZAÇÃO DOCENTE NA PERSPECTIVA DE DOCENTES}

No âmbito da pesquisa, buscou-se compreender, no grupo selecionado, aspectos relacionados ao campo profissional, como a formação, as condições de trabalho e a remuneração. Esses elementos se traduzem como importantes no contexto do nosso estudo, por isso, torna-se indispensável descrevermos o perfil de cada uma das entrevistadas.

Acerca da formação, das quatro professoras envolvidas na pesquisa, três possuem formação em nível superior: duas em Pedagogia (Iraildes e Maria) e uma em Matemática (Rosa). A professora Naiara declarou não ter formação em nível superior. Das professoras com nível superior, duas possuem pós-graduação e uma começou a cursar e desistiu, pois alegou que a carga horária de trabalho não permitia que ela continuasse. O Quadro 1, a seguir, aponta o perfil de cada uma das entrevistadas.

Quadro 1 - Perfil das professoras entrevistadas sobre a concepção de valorização docente

\begin{tabular}{|c|c|c|c|c|c|}
\hline Nome & Formação & Pós-Graduação & $\begin{array}{c}\text { Tempo } \\
\text { de } \\
\text { docência }\end{array}$ & $\begin{array}{c}\text { Carga } \\
\text { horária }\end{array}$ & Vínculo \\
\hline ROSA & $\begin{array}{c}\text { Matemática e } \\
\text { Administração }\end{array}$ & $\begin{array}{c}\text { Gestão Escolar e } \\
\text { Metodologia da } \\
\text { Matemática }\end{array}$ & 30 anos & $40 \mathrm{~h}$ & Efetiva \\
\hline IRAILDES & Pedagogia & $\begin{array}{c}\text { Psicopedagogia } \\
\text { e } \\
\text { Meuropedagogia }\end{array}$ & 10 anos & $40 \mathrm{~h}$ & $\begin{array}{c}\text { Contrata } \\
\text { da }\end{array}$ \\
\hline MARIA & Pedagogia & $\begin{array}{c}\text { Não concluiu a } \\
\text { pós-graduação }\end{array}$ & 9 anos & $40 \mathrm{~h}$ & $\begin{array}{c}\text { Contrata } \\
\text { da }\end{array}$ \\
\hline NAIARA & Ensino médio & Não possui & $\begin{array}{c}\text { Mais de } \\
30 \text { anos }\end{array}$ & $40 \mathrm{~h}$ & Efetiva \\
\hline
\end{tabular}

Fonte: Dados do questionário (2019).

Sobre não possuir formação em nível superior, Naiara declarou: 
Não busquei aperfeiçoar minha formação, não porque me acomodei. Eu trabalhava demais, não sobrava tempo para me especializar. (NAIARA, 2019).

As professoras Naiara e Maria, apesar de compreenderem a importância da formação inicial e continuada, alegaram não encontrar possibilidade de investimento na formação (Naiara na formação inicial e Maria na formação continuada), já que, além de faltar tempo, afirmaram ter trabalhos extras da escola que precisavam fazer em casa.

O artigo 67 da LDB estabelece que os planos de carreira e estatutos devam garantir por via de ingresso, por meio de concurso público, o aperfeiçoamento profissional, inclusive através de licenças remuneradas a progressão de carreira baseada na titulação e carga horária de trabalho que possibilite período reservado ao estudo.

Em relação à formação e o contexto no qual as políticas educacionais se configuram, o projeto de educação está vinculado aos interesses do desenvolvimento do mercado capitalista que, segundo Pinto (2014), prioriza:

1) a formação como preparação imediata para o trabalho, com ênfase na capacitação técnicooperativa e no desenvolvimento de habilidades para a adaptação; 2) a reprodução de conhecimentos em detrimento da produção de novos conhecimentos, o que se caracteriza pelo baixo investimento; [...] 5) a remodelação do investimento público na educação e o incentivo à privatização, resultando no exponencial crescimento do empresariamento da educação; 6) a quantificação das tarefas como critério de avaliação, progressão e promoção (PINTO, 2014, p. 663).

Sobre o motivo de ter escolhido a docência como profissão, as professoras Naiara e Rosa apontaram ser resultante de afinidade; a Professora Iraildes afirmou que escolheu a profissão por incentivo da família, e a Professora Maria informou:

Para te ser sincera, eu trabalhava em casa de família.

Eu comecei a olhar alguns cursos para eu fazer. Por 
ser um curso mais em conta, eu resolvi fazer Pedagogia. (MARIA, 2019).

A fala de Maria revela que o baixo custo do diploma ou maior facilidade de ingresso nos cursos de licenciaturas, muitas vezes, são motivos para a escolha da profissão docente. Apesar disso, como salientam Aranha e Souza (2013), a diversidade de condições da oferta e demanda por escolarização, tanto no que se refere à condição docente quanto à condição discente, aponta uma crise que atravessa a estrutura da pirâmide escolar de alto a baixo, e uma das explicações para essa crise na demanda pelas licenciaturas justificase "[...] pelo baixo valor do diploma de professor, sobretudo na educação básica, tanto no mercado de bens econômicos (salário) quanto no mercado de bens simbólicos (prestígio)" (ARANHA; SOUZA, 2013, p. 78).

Apesar do aumento da oferta de cursos de licenciatura, a profissão docente passa a ser cada vez menos cogitada. A baixa atratividade da carreira pode ser um dos fatores para o barateamento dos cursos de licenciatura, esse fato deve ser destacado, uma vez que a desvalorização social da profissão também se dá mediante o não cumprimento dos pilares que asseguram a valorização da carreira, o que a torna menos atrativa.

Sobre a questão salarial das docentes, a remuneração varia em circunstância do vínculo empregatício, tempo de serviço e a formação, como mostra o Quadro 2, seguinte.

Quadro 2 - Perfil sobre os elementos que envolvem a carreira das professoras entrevistadas

\begin{tabular}{|c|c|c|c|c|}
\hline Condições & Rosa & Iraildes & Maria & Naiara \\
\hline Formação & $\begin{array}{c}\text { Graduação } \\
\text { Pós-graduação } \\
(2)\end{array}$ & Graduada & Graduação & $\begin{array}{c}\text { Ensino } \\
\text { médio }\end{array}$ \\
\hline $\begin{array}{c}\text { Tempo de } \\
\text { serviço }\end{array}$ & 30 anos & 10 anos & 9 anos & $\begin{array}{c}\text { Mais de } 30 \\
\text { anos }\end{array}$ \\
\hline Vínculo & Efetiva & Contratada & Contratada & Efetiva \\
\hline
\end{tabular}




\begin{tabular}{|l|l|l|l|c|}
\hline Remuneração & $\mathrm{R} \$ 4.033,60$ & $\mathrm{R} \$ 2.956,00$ & $\mathrm{R} \$ 2.956,00$ & $\begin{array}{c}\text { Pouco } \\
\text { mais de } \\
\mathrm{R} \$ 3.000,00\end{array}$ \\
\hline
\end{tabular}

Fonte: Dados do questionário (2019).

A docente Naiara, que é professora há mais de 30 anos e não possui formação em nível superior, revelou que o valor de sua remuneração é um pouco mais de $\mathrm{R} \$ 3.000,00$ (três mil reais). Ao ser questionada quanto ao seu contentamento em relação à remuneração, Naiara alegou: "Em detrimento aos meus estudos e onde eu parei não me sinto insatisfeita". Apesar de alegar não ter dado continuidade a sua formação por falta de tempo, a professora parece responsabilizar a si mesma por sua estagnação na carreira. Essa lógica, oriunda de um modelo meritocrático, tem caracterizado - trabalho docente por uma implantação progressiva da individualização por mérito, que, segundo Silva (2012, p. 5), é "onde se espera a disposição dos trabalhadores em educação, o tempo todo, para realizar os objetivos e metas que Ihe são solicitados, em condições de trabalho desfavoráveis".

Esse modelo acaba por responsabilizar o professor pelo seu insucesso ou estagnação; assim, já que a remuneração está interligada a fatores como jornada de trabalho, carreira e formação profissional, isso interfere diretamente na remuneração docente.

O plano de carreira do município prevê os critérios de fixação do vencimento com base no tempo de serviço, habilitação e carga horária. Para isso, os planos de carreira devem possibilitar uma real progressão profissional, que esteja em conformidade com a formação e o tempo de atuação desses profissionais.

O grande problema se apresenta, ao que parece, quando a rede, além de dificultar as licenças para formação continuada, não cumpre as horas previstas de $1 / 3$ para o planejamento. Segundo os dados do sindicato, o município não garante o $1 / 3$ previsto por lei. As professoras do município recebem um valor de $16,7 \%$ a mais para complementar o tempo que elas deveriam ter para planejar. Valor que também não paga o tempo que elas não têm garantido. No ano de 2019, o município garantiu $1 / 3$ só para os professores que atuam 
no $1^{\circ}$ e $2^{\circ}$ ano, por conta do projeto voltado para a alfabetização, com objetivo de melhorar o índice no município.

Outro dado relevante do sindicato do município acerca da remuneração diz respeito ao Piso Salarial Nacional Profissional. O piso,

[...] além de definir um valor mínimo a ser pago aos docentes como salário base, também regulamenta a composição da jornada de trabalho desses profissionais, estabelecendo que $1 / 3$ do total de horas trabalhadas deve ser destinado à elaboração e ao planejamento das atividades docentes. (JACOMINI; NASCIMENTO; THOMAZINI, 2018, p. 1454).

O reajuste salarial dos docentes não tem sido repassado desde o ano de 2018. Neste ano os docentes que deveriam receber um reajuste de $6,81 \%$ receberam um repasse de $2,75 \%$ para o grupo com formação em nível ${ }^{6}{ }^{6}$, e os docentes de nível $\mathrm{I}^{7}$ receberam o repasse estabelecido. Nos anos de 2019 e 2020 não houve reajuste. Além de incoerente, essa questão faz-nos refletir se a valorização docente por meio da formação é de interesse dos gestores do município. Além disso, devemos questionar não só o impacto que o não incentivo à formação inicial e continuada causa na carreira e na remuneração docente, mas também as implicações disso na educação pública.

A respeito do que as docentes consideram valorização docente, a resposta de todas as professoras incluía sua efetivação por meio de salários mais dignos, melhores condições de trabalho, concursos para solidificação da carreira e o "suporte" dado pelos órgãos responsáveis. Esse suporte diz respeito às condições de trabalho, como pode ser observado no depoimento de Maria:

Olha, eu acho que a valorização que eles deveriam dar para a gente é uma condição melhor de trabalho,

\footnotetext{
${ }^{6}$ Nível II: referente ao Normal Superior, Pedagogia, licenciatura plena ou habilitação específica.

7 Nível I: referente ao Normal Médio ou Magistério.
} 
a pressão é muita e o suporte é pouco. Valorizar o professor em termos resumidos é dar ao professor melhores condições de trabalho. Eles cobram demais, mas não vê a realidade do local onde você trabalha. Eu que trabalho com Alfabetização ( $1^{\circ}$ ano do ensino fundamental) tenho poucos recursos para isso. $O$ espaço não tem televisão, impressora, não tem quase nada para o menino. Então, às vezes, você é quem tem que estar buscando e criando, então o tempo da gente é muito curto, já que a gente tem que ficar buscando fora os meios, né? Quando estou em casa, fico buscando meios para suprir essa falta. Fico cada vez com menos tempo. (MARIA, 2019).

Ainda que tenhamos professores bem formados, remuneração digna assegurada e planos de carreira estáveis, para a valorização da profissão é necessário observar, também, as condições de trabalho dos docentes, visto que as condições de trabalho e a carga horária podem trazer sobrecargas, descontentamento profissional e adoecimento, como apontamos anteriormente.

Ao serem questionadas se o trabalho afetava a saúde das docentes, com exceção de Naiara, todas as demais envolvidas mencionaram ter sua saúde de alguma forma afetada, associada ao trabalho que realizavam. Dores de cabeça, rouquidão e estresse excessivo foram os problemas citados pelas professoras. As condições de trabalho às quais o professor está submetido podem ser consideradas um fator agravante para o desenvolvimento de doenças físicas e psíquicas, como a Síndrome de Burnout (PAZ; SOUZA; PIRES., 2020).

Segundo Carlotto (2002), os maiores fatores de risco para o desenvolvimento de Burnout em docentes seriam a exposição contínua ao estresse, grande carga horária de trabalho e de atividades extraclasse e turmas com grande número de alunos. Por outro lado, na educação básica, alguns fatores de risco são ainda mais proeminentes, como a má valorização do trabalho, estruturas precárias e menor colaboração dos alunos, do que quando comparado ao ensino superior (PAZ; SOUZA; PIRES., 2020). Questões relativas à saúde docente estão associadas ao ambiente de trabalho e as condições da profissão, por esse motivo a necessidade da criação 
de políticas públicas que possibilitem melhores condições de trabalho e saúde para esses profissionais.

Ao serem questionadas sobre o que esperavam para que se sentissem realizadas como professoras, as respostas dadas pelas docentes apontaram que a maioria delas concorda que salários mais dignos, melhores condições de trabalho e reconhecimento social da carreira são elementos que as fariam se sentir mais valorizadas na profissão.

A respeito da necessidade de políticas públicas e assistência de órgãos governamentais e do que é necessário para que se sinta valorizada como profissional, a professora Rosa destacou: "dos órgãos governamentais nada espero a essa altura da minha vida profissional, porém eu me valorizo" (ROSA, 2010). Por mais que a lei ampare os elementos que asseguram a valorização docente, a fala da professora parece expressar descontentamento e desesperança na efetivação das políticas públicas de valorização do magistério. Isso pode se dar pelo fato de que, apesar de muitas políticas e por mais que estejam amparadas legalmente, elas não se efetivam na prática ou em sua totalidade.

A continuidade e acompanhamento da sociedade por prestação de contas a respeito das políticas implementadas podem, em parte, pressionar os que legitimam as políticas com base no interesse do mercado. Além disso, direitos garantidos por lei estão sendo descumpridos, o que permite inferir que só o amparo da lei não é suficiente para a garantia da efetivação da valorização do professor.

\section{CONSIDERAÇÕES FINAIS}

Mediante a apresentação das questões que envolveram este estudo sobre a valorização dos profissionais do magistério no contexto do município analisado foi possível chegarmos a algumas considerações. Primeiro, quanto à concepção de valorização docente, todas as participantes da pesquisa apontaram que para a efetivação da valorização do professor é necessário que sejam assegurados os elementos referentes à valorização desta profissão: formação adequada para exercer a sua função, carreira progressiva definida, um 
salário justo e compatível e condições propícias para o desenvolvimento do ensino e aprendizagem.

Segundo, evidenciamos, por meio da análise de algumas políticas de valorização expressas em documentos legislativos, como a Constituição Federal de 1988, LDB, PSPN e PNE, os avanços obtidos pela luta histórica travada pela categoria, na busca de assegurar a implementação e efetivação dessas políticas.

Além disso, é importante ressaltar que, por mais que a lei ampare elementos como piso salarial e plano de carreira, muitos municípios têm descumprido o previsto na legislação. O que promove não só o descontentamento do profissional atuante na carreira, mas a desvalorização social da carreira.

Ainda que a lei garanta para o professor o direito ao piso, ela não prevê nenhuma punição expressa para o município que descumprir a norma. Com isso, vários municípios, por motivos diversos, ainda não cumprem o pagamento do piso salarial, como é o caso do município em questão.

Concordamos com os autores consultados em relação à necessidade de efetivação dos pilares que assegurem a valorização do magistério. Através dos depoimentos das docentes pontuamos que questões como condições inadequadas de trabalho, não incentivo à formação, baixas remunerações e descumprimento do previsto no plano de carreira têm gerado não só insatisfação, mas descrédito por parte dos profissionais quanto à possibilidade de melhorias na carreira.

Portanto, observamos dificuldades inerentes ao exercício docente, dificuldades que poderiam ser amenizadas ou até sanadas se as políticas de valorização se efetivassem, ainda que o amparo da lei, por si só, não garanta o atendimento das reivindicações históricas. Por isso, ressaltamos que se faz necessária a participação coletiva da classe docente em diversas instâncias e espaços, a fim de exigir dos gestores públicos que os preceitos legais sejam cumpridos em sua plenitude. 


\section{REFERÊNCIAS}

ALVES, Thiago; PINTO, José Marcelino de Rezende. Remuneração e Características do Trabalho Docente no Brasil: um aporte. Cadernos de Pesquisa, São Paulo, v. 41, n. 143, p. 606-635, 2011. Disponível em: https://www.scielo.br/pdf/cp/v41n143/a14v41n143.pdf Acessado em: 28 maio 2019.

ARANHA, Antônio Vieira Soares; SOUZA, João Valdir Alves de. As licenciaturas na atualidade: nova crise? Educar em Revista, Curitiba, Brasil, n. 50, p. 69-86, out./dez. 2013. Disponível em: https://revistas.ufpr.br/educar/article/view/34745/21530. Acesso em: 19 set. 2018.

BARBOSA FILHO, Fernando de Holanda; PESSOA, Samuel de Abreu. A Carreira de Professor Estadual no Brasil: os casos de São Paulo e Rio Grande do Sul. Revista de Administração Pública, Rio de Janeiro, v. 45, n. 4, p. 965-1001, jul./ago. 2011. Disponível em: https://www.scielo.br/scielo.php?pid=S0034-

76122011000400004\&script=sci_arttext Acesso em: 12 mai. 2019.

BRASIL. Lei $n^{\circ}$ 5.692/71 de 11 de agosto de 1971. Fixa Diretrizes e Bases para o ensino de $1^{\circ}$ e $2^{\circ}$ graus, e dá outras providências.

Diário Oficial da República Federativa do Brasil: seção 1, Brasília, DF, p. 6377, 12 ago. 1971. Disponível em: https://www2.camara.leg.br/legin/fed/lei/1970-1979/lei-569211-agosto-1971-357752-publicacaooriginal-1-pl.html. Acesso em: 25 abr. 2019.

BRASIL. Constituição da República Federativa do Brasil de 1988. Diário Oficial da República Federativa do Brasil: Brasília, DF, 5 out. 1988. Disponível em: http://www.planalto.gov.br/ccivil_03/constituicao/constituicao.htm Acesso em: 27 abr. 2019.

BRASIL. Lei no 9.394/96. Estabelece as Diretrizes e Bases da Educação Nacional, Diário Oficial da República Federativa do Brasil: Brasília, DF, 23 dez. 1996. Disponível em: http://www.planalto.gov.br/ccivil_03/leis/19394.htm. Acesso em: 27 abr. 2019. 
BRASIL. Plano Nacional de Educação 2014-2024. Lei no 13.005, de 25 de junho de 2014, que aprova o Plano Nacional de Educação (PNE) e dá outras providências. Brasília: Câmara dos Deputados, Edições Câmara, 2014. Disponível em:

http://www.planalto.gov.br/ccivil_03/_ato20112014/2014/lei/l13005.htm. Acesso em: 15 de ago. 2019.

BRASIL. Lei n 8.112, de 11 de dezembro de 1990. Dispõe sobre o regime jurídico dos servidores públicos civis da União, das autarquias e das fundações públicas federais. Diário Oficial da República Federativa do Brasil: Brasília, DF, 12 dez. 1990 e republicado em 18 mar. 1998. Disponível em:

http://www.planalto.gov.br/ccivil_03/leis//8112cons.htm. Acesso em: 28 abr. 2019.

BRASIL. Leis, etc. Emenda Constitucional $n^{\circ} 53$, de 19 de dezembro de 2006. Dá nova redação aos arts. 70 , 23, 30, 206, 208, 211 e 212 da Constituição Federal e ao art. 60 do Ato das Disposições Constitucionais Transitórias. Diário Oficial da República Federativa do Brasil: Brasília, DF, 09 mar. 2007. Disponível em:

http://www.planalto.gov.br/ccivil_03/constituicao/emendas/emc/em c53.htm. Acesso em: 28 abr. 2019.

BRITO, Regivane dos Santos; PRADO, Jany Rodrigues; NUNES, Claudio Pinto Nunes. As condições de trabalho docente e o pósestado de bem-estar social. Tempos e Espaços em Educação, Aracaju, v. 10, n. 23, p. 165-174, set./dez. 2017. Disponível em: https://seer.ufs.br/index.php/revtee/article/view/6676. Acesso em: 21 jul. 2019.

CARLOTTO, M. S. A Síndrome de Burnout e o trabalho docente.

Revista Psicologia em Estudo 2002; Maringá; v. 7, n. 1, p. 21-29, jan./jun. 2002. Disponível em: https://www.scielo.br/pdf/pe/v7n1/v7n1a03.pdf . Acesso: dez. 2018.

CASTRO, Claudio Moura; IOSCHPE, Gustavo. Remuneración de los Maestros em América Latina: ¿es baja? afecta la calidad de la enseñanza? Documentos PREAL, Washington, n. 37, p.1-21, jan. 2007. Disponível em: http://www.preal.org/BibliotecaN.asp?Pagina=2\&ld_Carpeta $=64$ 
$\&$ Camino $=63 \% 7$ CPreal\%20Publicaciones $/ 64 \% 7 C P R E A L \% 20$ Docume ntos. Acesso em: 21 jul. 2019.

DOURADO, Luiz Fernando. Valorização dos profissionais da educação: Desafios para garantir conquistas da democracia. Revista Retratos da Escola, Brasília, v. 10, n. 18, p. 37-56, jan./jun. 2016.

Disponível em:

https://ei-

ieal.org/sites/default/files/docs/retratos_da_escola_18_2016.pdf. Acesso: 21 abr. 2019.

FARIAS, Adriana de Jesus Diniz. Políticas Públicas Educacionais e valorização docente. Rev. Eletrônica Pesquiseduca, Santos, v. 5, n. 10, p. 337-355, jul./dez., 2013.

GATTI, Bernadete Angelina; BARRETO, Elba Siqueira de Sá; ANDRÉ, Marli Eliza Afonso. Políticas docentes no Brasil: um estado da arte. Brasília: UNESCO, 2011.

GROCHOSKA, Marcia Andreia. Políticas educacionais e a valorização do professor: carreira e qualidade de vida dos professores de educação básica do município de São José dos Pinhais/PR. 271f. 2015. Tese (Doutorado em Educação) Universidade Federal do Paraná. Curitiba, 2015.

HYPOLITO, Álvaro Luís M. A valorização docente na perspectiva do Plano Nacional de Educação (2014-2024). Cad. Cedes, Campinas, v. 35, n. 97, p. 517-534. Dez. 2015. Disponível em: https://www.scielo.br/scielo.php?script=sci_arttext\&pid=S010132622015000300483\&lng=pt\&tlng=pt. Acesso: 21 abr. 2019.

JACOMINI, Márcia Aparecida; ALVES, Thiago; CAMARGO, Rubens Barbosa de. Remuneração Docente: desafios para o monitoramento da avaliação dos professores brasileiros no contexto da meta 17 do Plano Nacional de Educação. Arquivos Analíticos de Políticas

Educativas, Tempe, Arizona, n. 24, v. 73, 2016. Disponível em: https://dialnet.unirioja.es/servlet/articulo?codigo $=5623104$. Acesso em: 18 jul. 2019.

JACOMINI, Márcia Aparecida; NASCIMENTO, Ana Paula Santiago do; THOMAZINII Leandro. Carreira e Vencimento Base dos Professores 
da Rede Pública Paulistana. Educação \& Realidade, Porto Alegre, v. 43, n. 4, p. 1453, out./dez. 2018. Disponível em:

http://www.scielo.br/pdf/edreal/v43n4/2175-6236-edreal-2175623674835.pdf. Acesso em: 18 jul. 2019.

LUDKE, Menga; ANDRÉ, Marli E. D. A. Pesquisa em educação: abordagens qualitativas. Temas básicos de educação e ensino. São Paulo: EPU, 1986.

MONLEVADE, João Antônio Cabral de. Valorização salarial dos professores: o papel do Piso Salarial Profissional Nacional como instrumento de valorização dos professores da Educação Básica pública. 317f. 2000. Tese (Doutorado em Educação) - Universidade Estadual de Campinas, Campinas, 2000.

OLIVEIRA, Dalila Andrade. As reformas educacionais e suas repercussões sobre o trabalho docente. In: OLIVEIRA, Dalila Andrade (org.) Reformas Educacionais na América Latina e os

Trabalhadores docentes. Belo Horizonte: autêntica. v.1.p.13-38, 2003.

OLIVEIRA, Dalila Andrade. A nova regulação de forças no interior da escola: carreira, formação e avaliação docente. In: RBPAE. v. 27, n. 1, p. 25-38, jan./abr. 2011. Disponível em:

https://seer.ufrgs.br/rbpae/article/view/19917/11557. Acesso em: 22 jul. 2019.

\section{OLIVEIRA, Dalila Andrade. Políticas de formação e}

desenvolvimento profissional docente: da intenção às práticas.

2012. Trabalho apresentado ao $16^{\circ}$ Encontro Nacional de Didática e Práticas de Ensino, Campinas, 2012.

PAZ, Fernanda Ribeiro, SOUZA, Samuel, M.; PIRES, Ennia Débora P.

B. Condições de trabalho e saúde do Professor: fatores relevantes para o desenvolvimento da síndrome de Burnout. In: NUNES, Claúdio Pinto (org.). Condições de trabalho e saúde do professor. Vitória da Conquista, Edições UESB, 2020. p. 93-109.

PINTO, Marina Barbosa. Condições sócio-ocupacionais do trabalho docente e a formação profissional. Serv. Soc. Soc., São Paulo, n. 120, p. 662-676, dez. 2014. Disponível em: 
http://www.scielo.br/scielo.php?scipt=sci_arttex\&pid=S010166282014000400004\&lng=pt\&nrm=iso. Acesso em: 17 jul. 2020.

SCHEIBE, Leda. Valorização e formação dos professores para a educação básica: questões desafiadoras para um novo Plano Nacional de Educação. Educ. Soc., Campinas, v. 31, n. 112, p. 9811000, jul./set. 2010. Disponível em:

https://www.scielo.br/pdf/es/v31n112/17.pdf. Acesso em: 12 set. 2019.

SILVA, Amanda Moreira. Precarização do trabalho docente e meritocracia na educação: o olhar empresarial dos governos e a resistência do professorado da rede pública do Estado do Rio de Janeiro. In: SIMPÓSIO NACIONAL ESTADO E PODER: Sociedade civil, 7, 2012, Uberlândia, Anais Eletrônicos [...] Uberlândia, 2012.

Disponível em: http://www.historia.uff.br/estadoepoder \&gt;. Acesso em: 03 jul. 2020.

SILVA, Daniela Oliveira Vidal da; NUNES, Claudio Pinto. Plano de carreira enquanto estratégia de resistência para a valorização docente no território de identidade do sudoeste baiano. Revista Educação e Emancipação, São Luís, v. 12, n. 3, set./dez. 2019. Disponível em: http://www.periodicoseletronicos.ufma.br/index.php/reducacaoema ncipacao/article/view/12403. Acesso em: 24 jul. 2020.

VALENTE, Ivan; ROMANO, Roberto. PNE: Plano Nacional de Educação ou carta de intenção? In: Educação e Sociedade, Campinas, v. 23, n. 80, p. 96-107, set., 2002. Disponível em: http://www.scielo.br/pdf/es/v23n80/12926.pdf. Acesso em: 21 abr. 2018.

WEBER, Silke. O Plano Nacional De Educação e a Valorização Docente: Confluência do debate nacional. Cad. Cedes, Campinas, v. 35, n. 97, p. 495-515, set./dez., 2015.

Submetido em: Agosto/ 2020.

Aceito em: Janeiro/ 2021. 